\title{
Software Design for Oil Industry Metrology Systems
}

\author{
Viorel Costin BANTA ${ }^{1}$, Dorian COJOCARU ${ }^{1}$, Mihnea Alexandru MOISESCU ${ }^{2}$, \\ Ioan Stefan SACALA ${ }^{2}$ \\ ${ }^{1}$ Faculty of Automation, Computers and Electronics, University of Craiova, \\ Craiova, Romania, \\ bantaviorel@gmail.com; cojocaru@ robotics.ucv.ro \\ 2 Automatics and Computer Science Faculty, University Politehnica of Bucharest, \\ 313 Splaiul Independentei, Bucharest, Romania, \\ cmamihnea@gmail.com; sacalaioan@yahoo.com
}

\begin{abstract}
This paper focuses on the integration of metrology principles in Enterprise Resource Planning (ERP) systems. The authors discuss the development methodology and the implementation of a metrology oriented software application for the calibration of oil reservoirs. The application is integrated with an existing Enterprise Resource Planning (ERP) system of a large oil and gas company. The software application was developed in the SAP (System and Applications Products) programming environment ABAP (Advanced Business Application Programming), using the latest Web Dynpro WD technology. The development methodology includes the analysis, implementation and testing of the software application. The application includes models: dispatcher model, body-leasing model, calibration given outside (fixed price). The metrology software application is presently being tested in a large oil and gas company and handles the management of tank oil calibration.
\end{abstract}

Keywords: Enterprise Resource Planning, Metrology System, Cyber-Physical Systems

\section{Introduction}

Enterprise resource planning (ERP) is business process management software that allows an organization to use a system of integrated applications to manage the business and automate many back office functions related to technology, services and human resources [1]. This concept, ERP-"Enterprise Resource Planning", was introduced in 1990 by the Gartner Group, in order to define a new generation of manufacturing resource planning (MRP II) software, which later came to fill up the gap reflected by the evolution of application integration beyond manufacturing. The Gartner Group its client's oriented company which has as a main field of activity, IT solutions consultancy. MRP II is a method which helps companies, to involve the planning of all the regular resources, including without limitation, software applications, users skills and abilities, design of specific databases, and any other computer resources [1] [22] [23]. The concept purpose is to manage accurate the resources, in order to increase the performance and most of the productivity of the company [1], [2]. For developing activity in a company, initially for each division where used separate software, accounting, business intelligence, human resources, inventory management, planning, manufacturing, sales, marketing, later came the ERP concept and his final target was to integrate all these software applications in one single software product [4]. Overall the ERP has improved the process management of a business activity, he integrated and managed applications for all areas.. SAP, Oracle and Microsoft are the more well-known companies which deliver ERP software for large enterprises. SAP started in 1972 in Germany, is the largest inter-enterprise software company in the world, and one of the largest independent software supplier. The initial purpose of SAP was to provide to his customers the possibility to interact with a common corporate database for a broad software application. ESR it's a new trend in SAP evolution. "Enterprise Services Repository is the central repository, which is part of SAP NetWeaver platform, where enterprise services, business objects, and business processes and their metadata is stored" [6]. More or less ESR is the central repository information used in entire SAP NetWeaver Platform and if we want to make our application callable by services and integrated with other applications or business partners we have to use the principles of ESR [7]. From this paper's point of view, the interesting aspect is that we create a z-homemade application inside our installed enterprise resource planning software (SAP) [10]. One used database for SAP is IBM DB2/DB6 which has the roots the beginning of the 1970 . 


\section{Premises for the Development of Enterprise Systems based on Cyber Physical Systems and Internet of Things principles.}

Research in the area of Cyber-Physical Systems and Internet of Things has seen a tremendous development over that last few years, involving more and more entities and providing new solutions for problems both in business and manufacturing areas.

Cyber-Physical Systems are defined by the National Science Foundation as engineered systems that are based on the synergy of computational and physical components. The aim is to extend control theory to networks of devices but not necessarily at internet scale.

A Cyber-Physical System is composed of:

- Physical components: physical objects,

- Cyber-Physical interface devices: sensors, actuators,

- Cyber Systems: computing devices and communication networks.

Sensors are devices that react to change in physical process and transmit a resulting impulse. A smart sensor has a processing unit and a communication interface thus processing the obtained data and communicating with other devices. Smart sensors bring the processing power closer to the point of measurement, and extend the sensing capability by using communication networks." (Sacala, Repta, Moisescu 2013)
"Actuators are mechanical devices that act upon physical objects by applying force or torque. Smart actuators are actuators controlled by devices equipped with processing units (Programmable Logical Computers). (Sacala, Repta, Moisescu 2013)

Using CPS and IoT concepts, Enterprise System can extend their capabilities towards the ability to "sense" both the internal and external environment. (Moisescu, Sacala 2014)

Other enabling building blocks for CPS oriented Enterprise Systems are:

- Smart environments represent environments that use data acquisition through sensors to describe its state, generate information and adapt to its inhabitants in order to improve predefined characteristics.

- Distributed Sensor Networks are networks of data acquisition that provide functions such as: collecting data, monitoring, processing, and decision-making.

- Context sensing as a capability provided by distributed sensor networks. By integrating different types of sensors such networks provide heterogeneous information flows

- Knowledge management provides organization methods to deal with: explicit knowledge, and tacit knowledge.

The main characteristics of Systems developed using the proposed framework are:

- Capable of using virtual and physical resources at the same both sensing and actuating in real and virtual environments

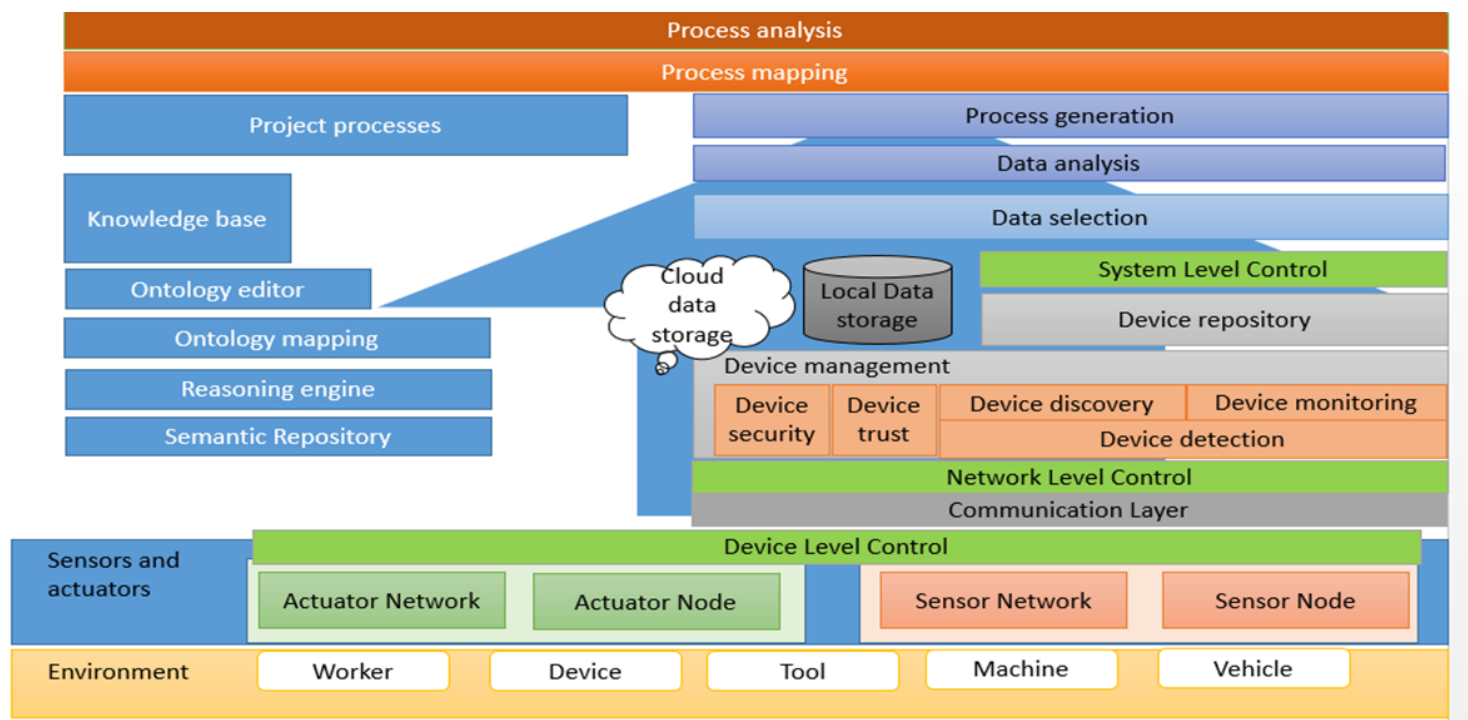

Figure 1.a. CPS oriented Enterprise System architecture 
- Capable of acquiring, generating and processing "big data"

- Acquiring data from heterogeneous resources form physical and virtual environments

- Reacting based on simple rules such as "ifthen-else"

- Executing simple to complex behaviours based on generated events

- Adapting to changing environments based on simple to complex schemas

- Transforming business processes as to incorporate in execution sensor data

- Integrating Distributed Systems

- Communicate in large-scale systems

- Capable of constructing scalable systems

Several views designed in order to characterize the proposed framework are presented:

- Environment view taking into account the structure along with the internal policies rules and values.

- Sensor and Actuator View including constrains generated by complex environments and operation

- Network view including the technologies needed for data transfer and node communication.

- Process view including process represented as an abstractization of core business practices, relationships between different entities, the acquisition, flow, transformation and exploitation of data and information and the products and services.
As presented in the generic architecture in fig 1.b a CPS oriented Enterprise System Data Acquisition view has 3 important layers (Dumitrache, 2013), (Sacala, 2013):

- Business Process Layer- consists of the existing processes both core and support, used in the enterprise and the new modelled processes focused on IoT and CPS principles.

- Business Processes, both core and support ones, execution engines, process repositories. Other business applications: middleware, relational databases.

- Physical Layer - including entities both physical and their virtual representation that acquire data from the enterprise environment (sensors), act, modifying the environment (actuators) and transmit and receive data and commands with designated mechanisms (network): Sensors and Actuator Networks, Wireless sensors networks.

Entities defined in the Physical layer have the following basic characteristics:

- Sensing capability: data acquisition, primary data analysis and sensor data fusion;

- Identity: addressability, traceability and type;

- Network and interface layer: communicate with enterprise systems with workers and other entities

- Action capability: capacity to change the environment.

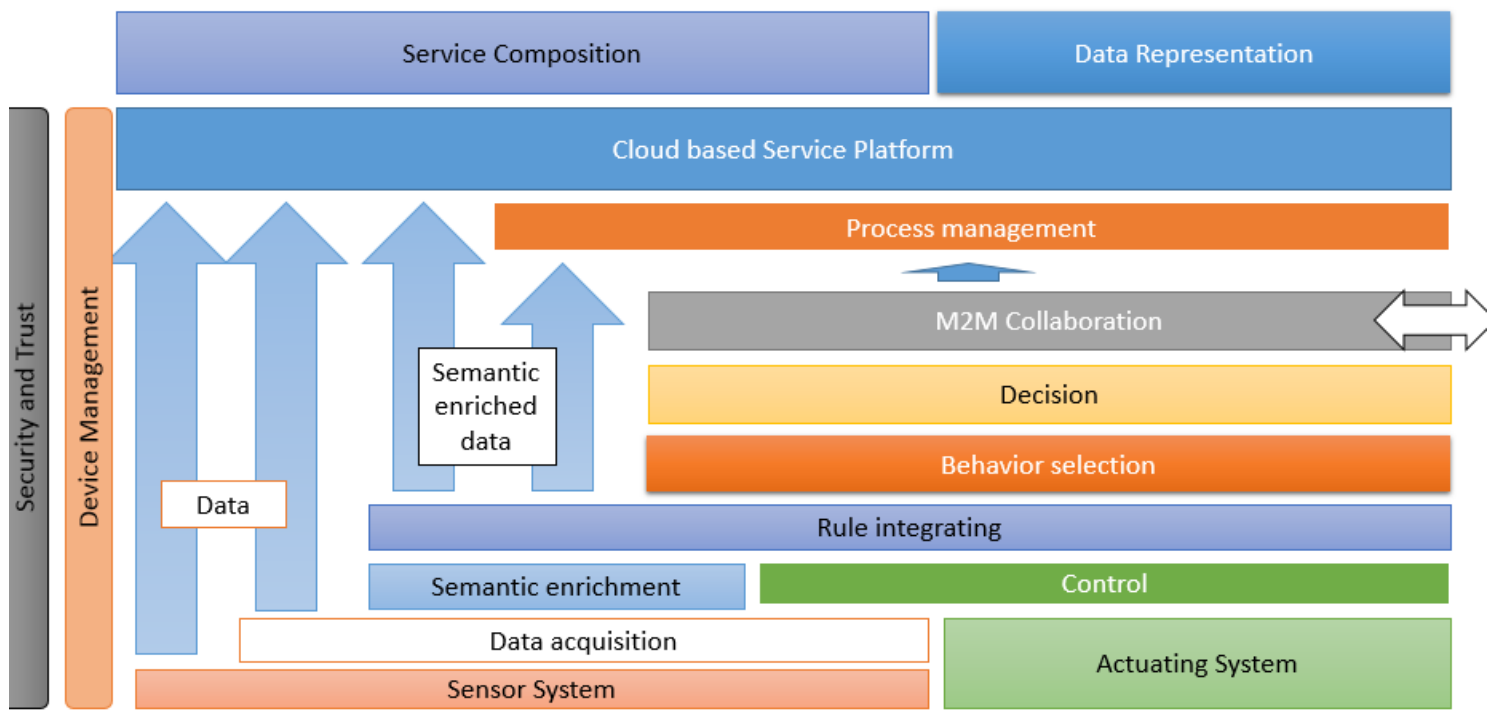

Figure 1.b. CPS oriented Enterprise System Data Acquisition view 
- Reaction capability: Entities are capable of reacting to predefined changes in the environment.

- Trust: ability to manage the trust level and to integrate in a trusted and secure network.

- Security: integrity of data acquired and transmitted through the network

\section{Methodologies for Calibration of Oil Reservoirs, Software Requirements Specification.}

Using new software technology, in fact ESR, is part of daily activity inside oil companies, which try to automate processes, in order to have an accurate visibility of their innovations and to adapt several changes shortly and with better results [5], [6]. In order to achieve this, many companies create development teams dedicated to solve the problems of each specific activity. In entire group, the development team (inside Technology Department) is dedicated for developing and providing best practices for internal processes, in order to help the daily activity of their colleagues from other departments. All developments are stored in SAP Solution Manager - Development Center tool. In order to have an accurate integrated database with all measurements regarding calibration of oil reservoirs, test results, conclusions after measurements, we initiate a process / case study in order to create an internal development application for metrology area, calibration reservoirs inside SAP system. Our case study full fills all legal requirements regarding this subject. In exploration and production area we can use two types of reservoirs: vertical and horizontal (Figure 2a. and Figure 2.b).

In order to realize a calibration of an oil reservoir a mixed method is used. The method is based on two components: a volumetric one and a geometric one [14]. This method is used to calibrate a vertically cylinder reservoir with fixed roof. This reservoir cannot have a nominal capacity greater than 40 cubic meters [13].

To implement this method for the calibration purposes, two components are used:

- geometric components are used for direct measurement reservoir dimensions based on measuring tapes, the final result regarding entire capacity of reservoir being determined based on measurement performed [13],[14];

- geometric components are used for direct measurement reservoir dimensions based on measuring tapes, the final result regarding entire capacity of reservoir being determined based on measurement performed [13],[14];

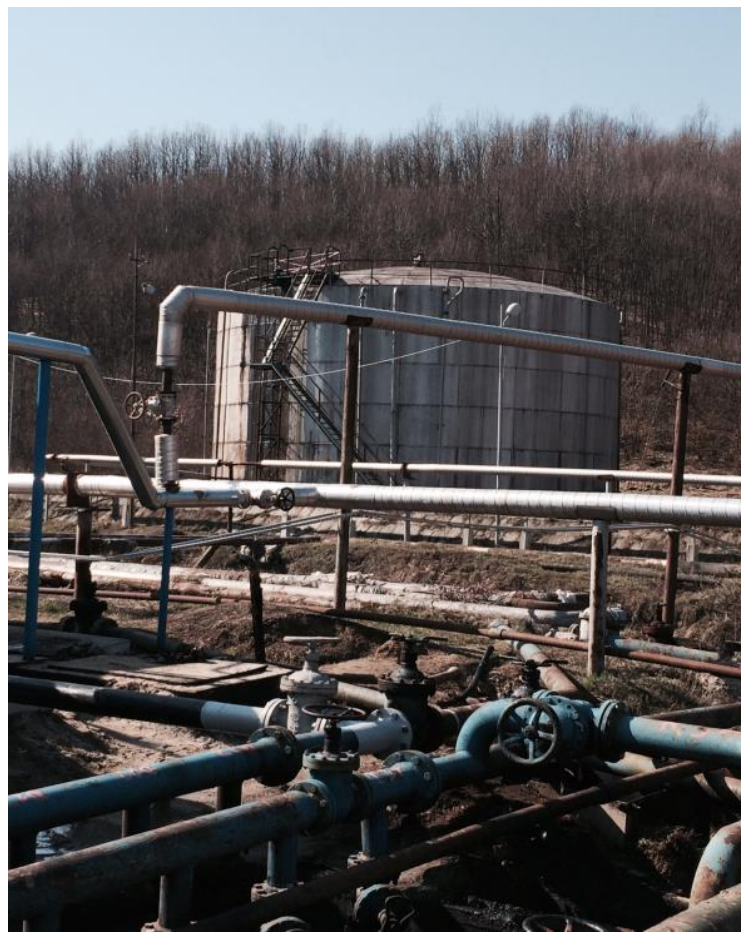

Figure 2.a. Vertical reservoir / tank

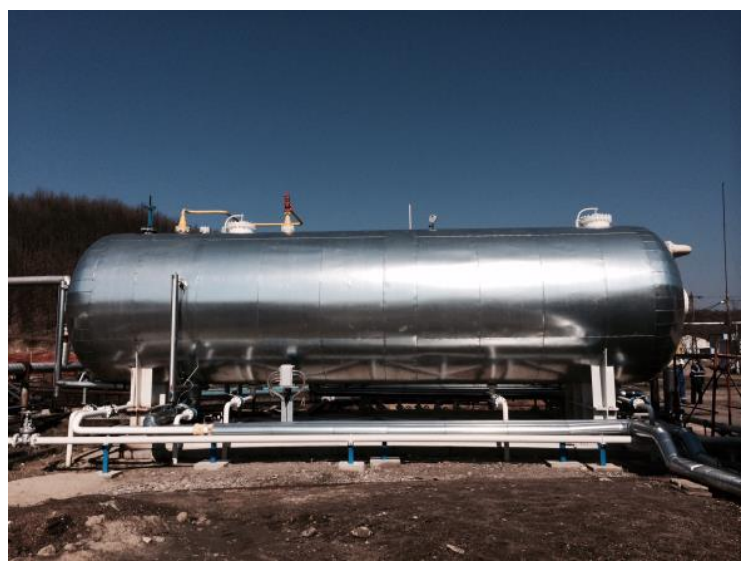

Figure 2.b. Horizontal reservoir / tank

Mixed method cannot be applied to tanks with obvious deformity and to tanks which do not have a circular horizontal section. In order to verify and calibrate a reservoir it's used a different metal measurement unit (with overflow): $100 \mathrm{dm}^{3}$ (cubic decimeter), $200 \mathrm{dm}^{3}$, $500 \mathrm{dm}^{3}$ or higher than this value. If is needed to measure with other standard fraction, then we will use, a measure of $50 \mathrm{dm}^{3}$ [13], [14]. 
In order to see the underlying principles to create a software application, the Figure 3 illustrated this, so, we take into consideration the metrology standard rules, guidelines, principles, standards and indications from the internal metrology team. In the application all recorded information is stored in order to be analyzed and to be part of the mathematical computations. When the collecting measurements process is started, it is needed to create a calibration table for each reservoir. For each value of partial capacity from the reservoir, and for each integer value expressed in centimeter of the filling height of the tank, the reference temperature will be $20^{\circ} \mathrm{C}$ [10].

We notice that $\mathrm{V}_{\mathrm{H}}$ is partial capacity, corresponding to the higher fill $\mathrm{H}$ (integer number recorded in centimeter), between consecutive two measured heights, $\mathrm{h}_{\mathrm{i}-1}$ and $\mathrm{h}_{\mathrm{i}}$, and will be obtained using the linear interpolation, using the following formula [13], [14]:

$$
V_{H}=V_{i-1}+v_{i} \times \frac{H-h_{i-1}}{h_{i}-h_{i-1}},(i=1,2, \ldots n)
$$

where:

- $k=1,2 \ldots i$ - order number of ratio water introduced; $h_{0}=0$;

- $\quad v O=$ dead stock of reservoir,
- $v_{1}, v_{2} \ldots v_{i}$-ratio water volume which are placed in reservoir, successively, to the height $h_{i}$,

- $h_{1}, h_{2} \ldots h_{i}$ - each measured height, after ratio water placed.

$V_{i-1}=\sum_{k=0}^{i-1} v_{k}$

For each measurement we have to take into consideration the outside temperature. In this case, regarding $\mathrm{v}_{\mathrm{k}}$, there are two cases:

- when it is not considered, then the amount of sum of all capacity, will be equal with all ratio water introduced in reservoir [13], [14];

- or we have to adapt our calculation with one correction factor, equal with (1-e)/100 (e is the corrected error, in percentage, of the working flow meter) [13], [14].

Regarding the avoidance of water expansion effect, there are also two cases:

- when the water temperature is between 50 $\mathrm{C}$ and $100 \mathrm{C}$ and the difference between average measure volume and the reservoir does not exceed $20 \mathrm{C}$,

- when the water temperature is between 100 $\mathrm{C}$ and $250 \mathrm{C}$ and the difference between

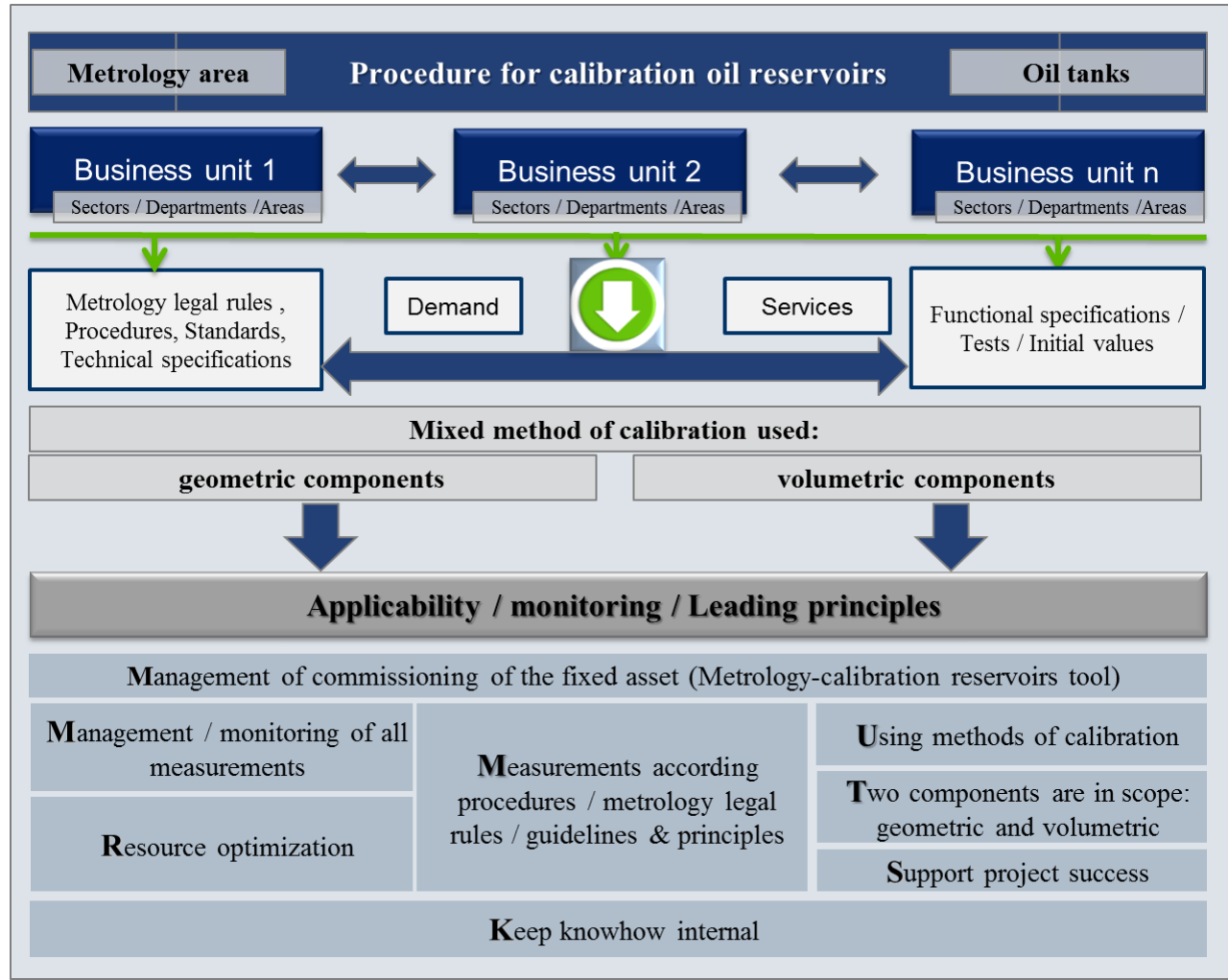

Figure 3. Example metrology procedure / connection between business areas 
average measure volume and the reservoir does not exceed $10^{\circ} \mathrm{C}$.

For some different water ration at $t_{k}$ temperature, the relation (1) can be corrected, using the following formula [13], [14]:

$v_{k}\left(t_{k}\right)=v_{k}(20) \times\left[1+\beta_{e}\left(t_{k}-20\right)\right]$,

where:

- $\quad k$ - is the order number of ratio water,

- $v_{k}\left(t_{k}\right)$ - is the ratio water volume on $t_{k}$ temperature;

- $v_{k}(20)$ - is the amount of the real conventional capacities for the water measure, which is used for the achievement water ratio;

- $\quad \beta$ - is the coefficient of expansion in volume of the material volume ratio of which is made.

These corrections are also made for the dead stock $v_{0}$. In order to calculate water mass, $m_{k}$, taking in consideration volumes $v_{k}\left(t_{k}\right)$ we can use the following formula [13], [14]:

$m_{k}=v_{k}\left(t_{k}\right) \times \rho\left(t_{k}\right), k=0,1, \ldots, i$,

where: $\rho\left(t_{k}\right)-$ the density of water at the $t_{k}$ temperature.

The following formula is used to compute the water mass $M_{i-1}$ till high $h_{i-1}$ [13], [14]:
$M_{i-1}=\sum_{k=0}^{i-1} m_{k}$,

In order to calculate the water volume of our reservoir, $V_{i-1}$, at $h_{i-1}$ and $t_{i-1}$ the following formula is used [13], [14]:

$V_{i-1}\left(t_{i-1}\right)=M_{i-1} / \rho\left(t_{i-1}\right)$,

where: $\rho\left(t_{i-1}\right)-$ is water density at $t_{i-1}$ temperature.

The capacity of reservoir, $V_{i-1}(20)$, for height $t_{i-1}$ and reference temperature $20^{\circ} \mathrm{C}$, will be calculated [13], [14]:

$V_{i-1}(20)=V_{i-1}\left(t_{i-1}\right) \times\left[1+\gamma_{r}\left(20-t_{i-1}\right)\right]$,

where $\gamma_{\mathrm{r}}=(2 / 3) \times \beta_{\mathrm{r}}$ is the dilatation coefficient of the reservoir material.

A correction for temperature could be applied during the calibration of a reservoir if the water height $h_{i}$ is considered. This correction could be ignored if the height is lower than $2 \mathrm{~m}$ or if the height is upper than $2 \mathrm{~m}$ and water temperature into the reservoir is between $15^{0}-25^{0} \mathrm{C}$. The following formula is applied [13], [14]:

$h_{i}\left(t_{i}\right)=h_{i}(20) \times\left[1-\alpha\left(t_{i}-20\right)\right]$,

where:

- $h_{i}\left(t_{i}\right)-$ is the height at the temperature $t_{i}$, which is measured in the reservoir;

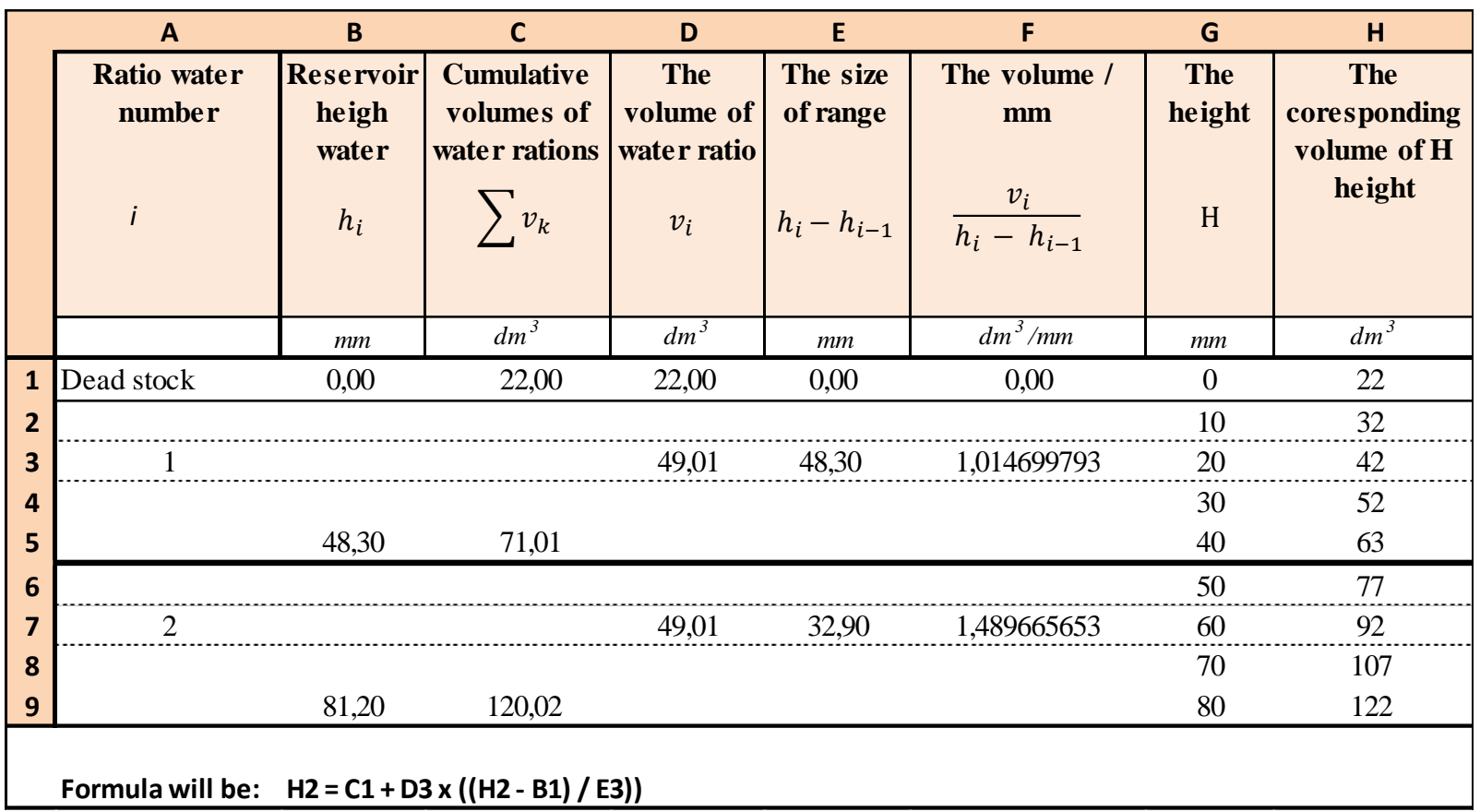

Figure 4 The result of a calibration 
- $\quad h_{i}(20)$ - is the height read from measuring tape, according with the calibration certificate which is attached to the measuring tape;

- $\alpha$ - the material coefficient of linear dilatation;

In order to perform the calculations, the following dilatations coefficients are used: the mild steel $-3,3 \times\left(10^{-5}\right)^{0} \mathrm{C}$; stainless steel: $5,1 \mathrm{x}$ $\left(10^{-5}\right)^{0} \mathrm{C}$; aluminium alloy - 3,3 x $\left(10^{-5}\right)^{0} \mathrm{C}$; brass: $3,3 \times\left(10^{-5}\right)^{0} \mathrm{C}$. In each measurement the calculated value of height is rounded on integer value [10], [13], [14]. As a conclusion, the calibration sheet will include the ratio water number, the reservoir/tank height water, the cumulative volumes of water rations, the volume of water ratio, the size of range, the volume/mm, the height and the corresponding volume of height as is described in the Figure 4.

\section{Metrology Software Application Design}

sSAP focuses on existing integrated processes in the company, from the collecting, planning process, development/production tracking and to the purpose of managing the relationships with customers, suppliers or other business partners. SAP (System and Applications, Products) is the largest ERP (Enterprise Resource Planning) system in the world [15]. SAP is based on client/server architecture and it is used in developing integrated systems.

The benefits for the company, when choosing to use SAP, are as following: an integrated system (there is a single database, all components are interdependent); an open system (independent from the hardware platform and database used, allowing the correlation with other software; modification including new functions created by the user; a comprehensive system that, from an economic perspective, can cover any sector activities; a real-time system including tools and providing information based on data analysis from operational flow; a lower cost for company based on automated tools and preconfigured functionality; an integrated industry-specific solutions inside business processes; easy to integrate operations into one software in order to meet the corporate needs for standardization and control.

As it was used for the application WebDynpro, other benefits come with this new technology for SAP landscapes, like: the model is used for develop professional Web UI's (Web User Interface) for business applications; the WD tools can support the application development during all phases (implementation, design); a clear separation between layout data and business data, thus it is possible to develop WD applications with the same programming model, both for conventional PC's and mobile devices; different languages are supported; the time for implementation and the effort implementation is significantly reduced; a structured design process is supported by WD; it's easy to use the Model View Controller concept obtaining a strict separation of layout data and business data.

In the Figure 5 is explained the WD concept and his benefits. In another train of thoughts the concept of WD are based on MVC (Model View Controller) architecture and is composed of three particular elements: model, controller and view.

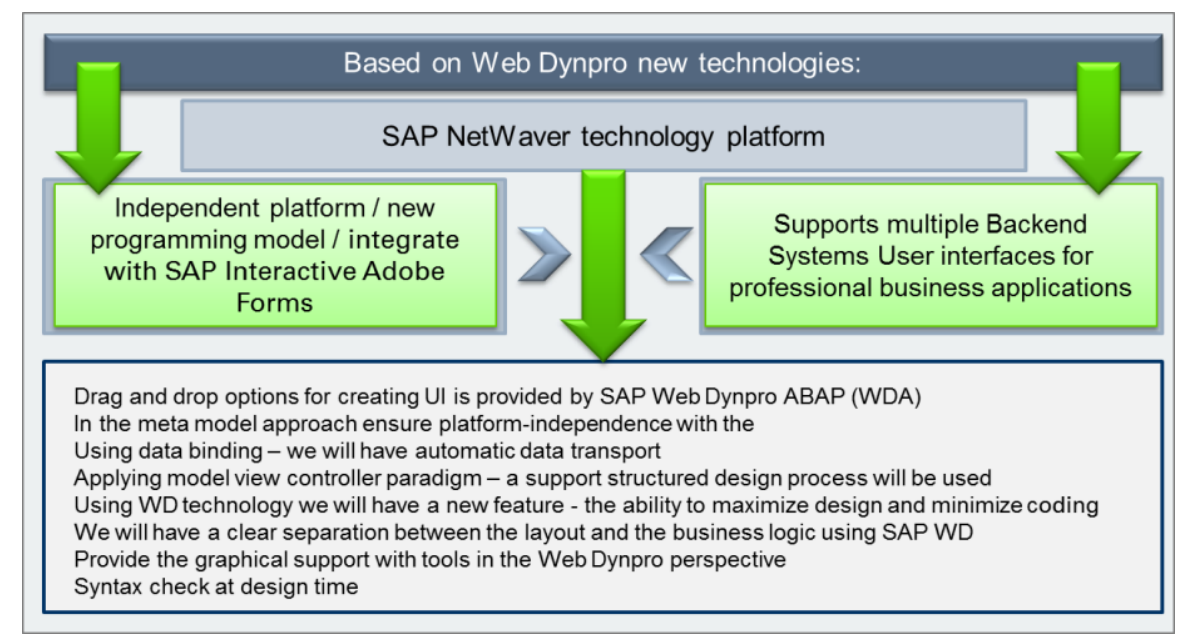

Figure 5. The result of a calibration 
The MVC architecture is described in the figure below, Figure 6. As it is plotted in this figure, the MVC architecture design pattern contains a clear distinction between processing control (controller), data model (application data, connection to business functionality), and the display of the data (view) in the interface according with clear rules.

As described in the Figure 6 different types of controllers are available: component controller, custom controller, interface controller, view controller and window controller. Enhancements in WD ABAP can be done easily using the functionality called Enhancement Options (ABAP WD components cannot be implemented using BADI - BADI's are ABAP object based of changes, instead of the more common subroutines/function modules).

This is an explicit anchor points provided by SAP and is implemented in the source code at suitable points during the development of the WD components [10].

As an experience, using these options provided by SAP (enhancement options) it is possible to insert a separately developed BADI into the flow of the program and therefore each BADI is an explicit enhancement. For the WD components, several enhanced implementations can be created and all are independent of one another, so it is possible to add, in addition to source code, enhancements: in a view, in a controller, in a component and window. An important aspect in WD flow is the context, which is a method of storing data in a hierarchical manner. The data used by the component or a view is stored in the form of context [6]. The controller can be used to read or write data in the context, as a starting point. In order to create a WD application it is compulsory to use the normal tcode (SAP transaction) se80 and to choose in the repository browser the particular WebDynpro component/interface.

\section{Implementation Principles for the Software Application}

Calibrations are part of planned activity inside companies, which try to supervise the integrity and legality of his fixed assets - here we are talking about reservoirs which are subject of metrological control. The Metrology tank calibration application structure was created based on request from Demand Management business division. Programming has been done using the ABAP (Advanced Business Application Programming) programming language. ABAP was one of the first programming languages that included the concept of Logical Databases (LDBs), which provided a high level of abstraction in the database. The latest version of ABAP includes object oriented programming.

In the beneficiary Oil Company, in particular Exploration \& Production division, this implementation has been considered a success. The application was done based on a detailed analysis of the business environment, taking into account all requirements from exploration business and all BRML legal requirements. The application interfaces from Figure 7 show, step by step, the "in house development" SAP solution for demand management business. The innovation of this development is that

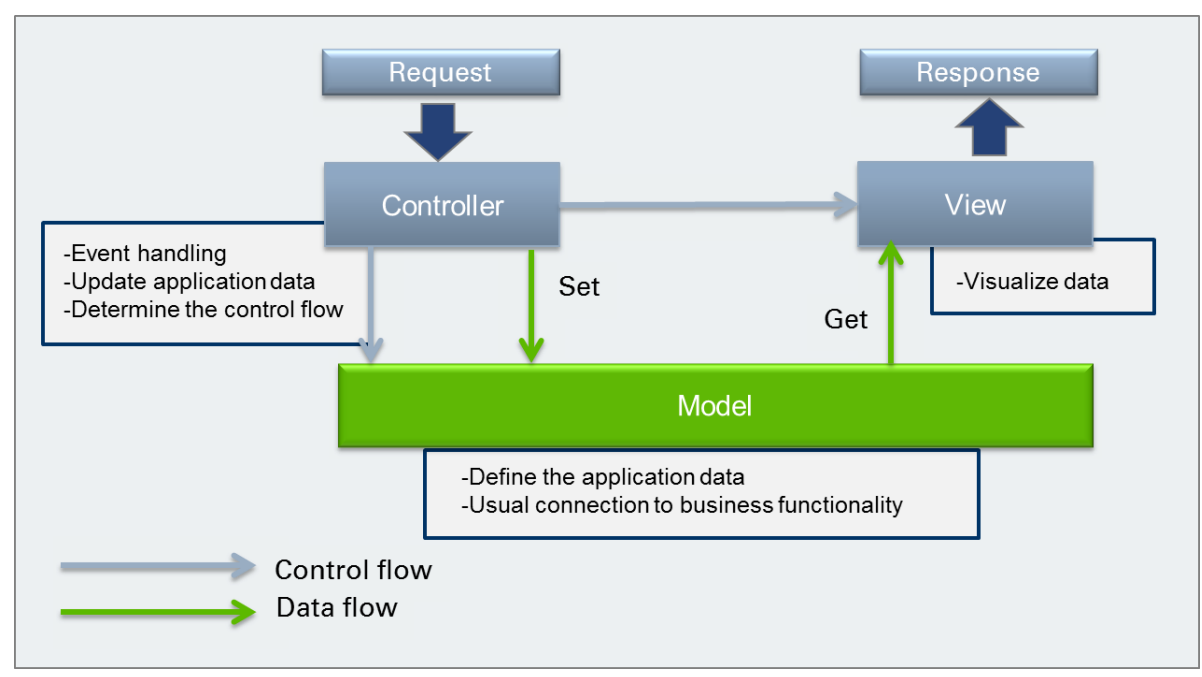

Figure 6. The MVC architecture 


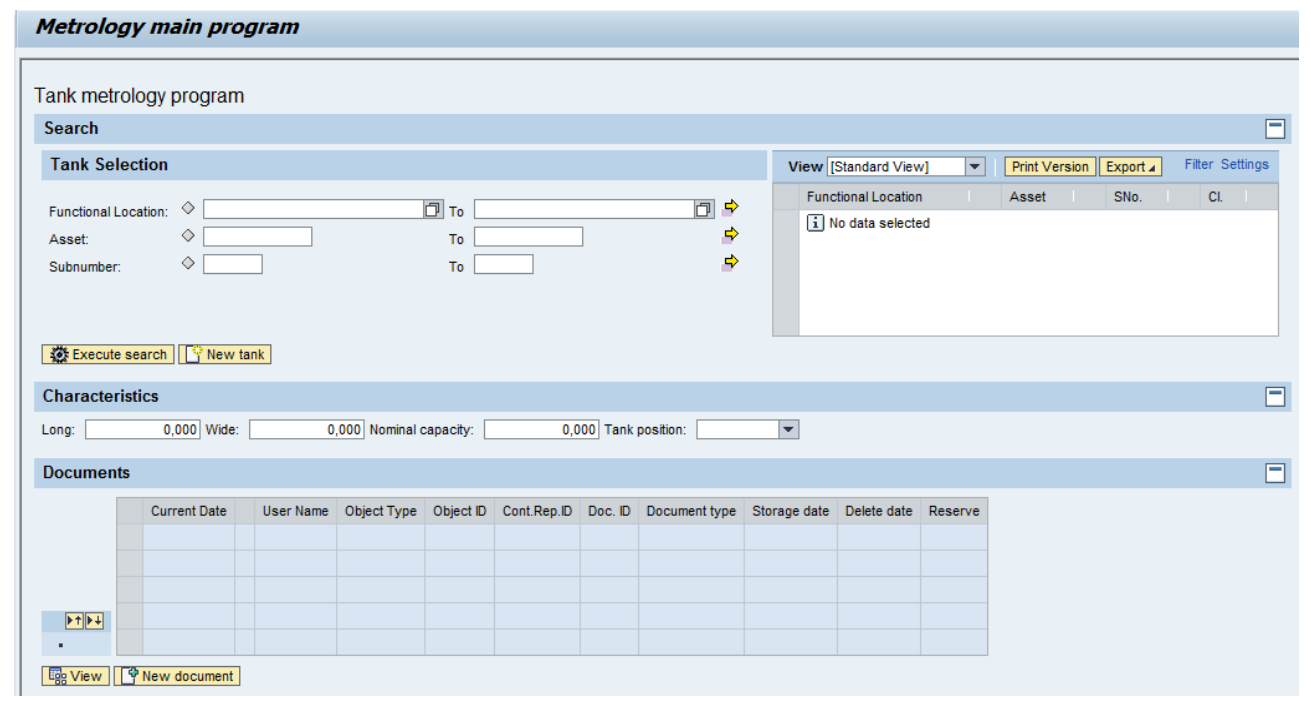

Figure 7. The application interface

everything was developed in the latest technology provided by SAP, WebDynpro WD - a web application technology. Due to this development each end-user will be able to access the application via web. In order to see the content of it, this application will be published via SAP Portal servers. In order to perform the oil tank calibration record in the tool, it is necessary to collect the data from the oil sectors. This data will be filled in specific forms, according to the BRML legislation. Next step is adding the equipment data which is going to be calibrated; this data can be taken from the fixed assets module. Another step will be adding technical data, like: materials, external dimensions - length, height and width; the entire capacity; max gross weight; tank position. In particular, we can also add additional fields, where a different type of technical data can be stored, the tool developed by us, being a customizable one. In Figure 8 it is plotted the form used for entering the above mentioned information. In addition to this process, all documents that have been provided from the company which sales the oil tank, are being stored in the system, in order to be viewed at any time [10].

By using our tool, the E\&P division has the major benefit of viewing all the data for metrology calculation/calibration in one database. The data introduced in the system is accurate and can be displayed on-line. The legal entities can audit the data at any time in order to verify if the algorithm used for calibration is used correctly [10].

Based on a chosen calibration method and after all technical characteristics are added / stored in the tool, we have the possibility to upload, step by step, the data provided from the oil sectors,

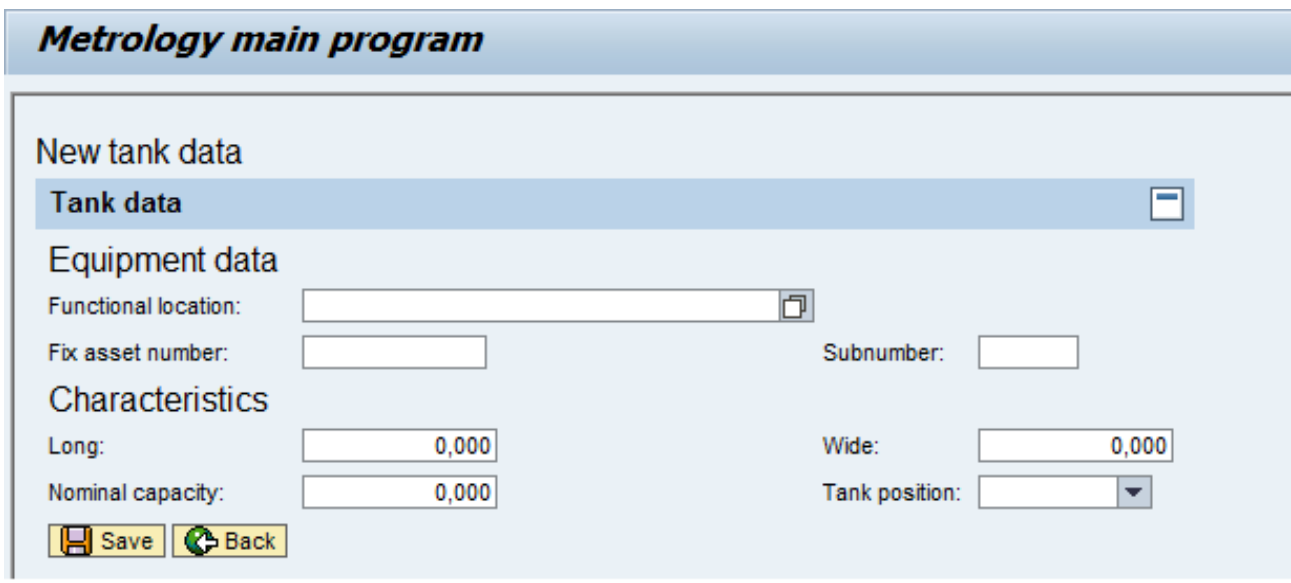

Figure 8. SAP Metrology add new oil reservoir 


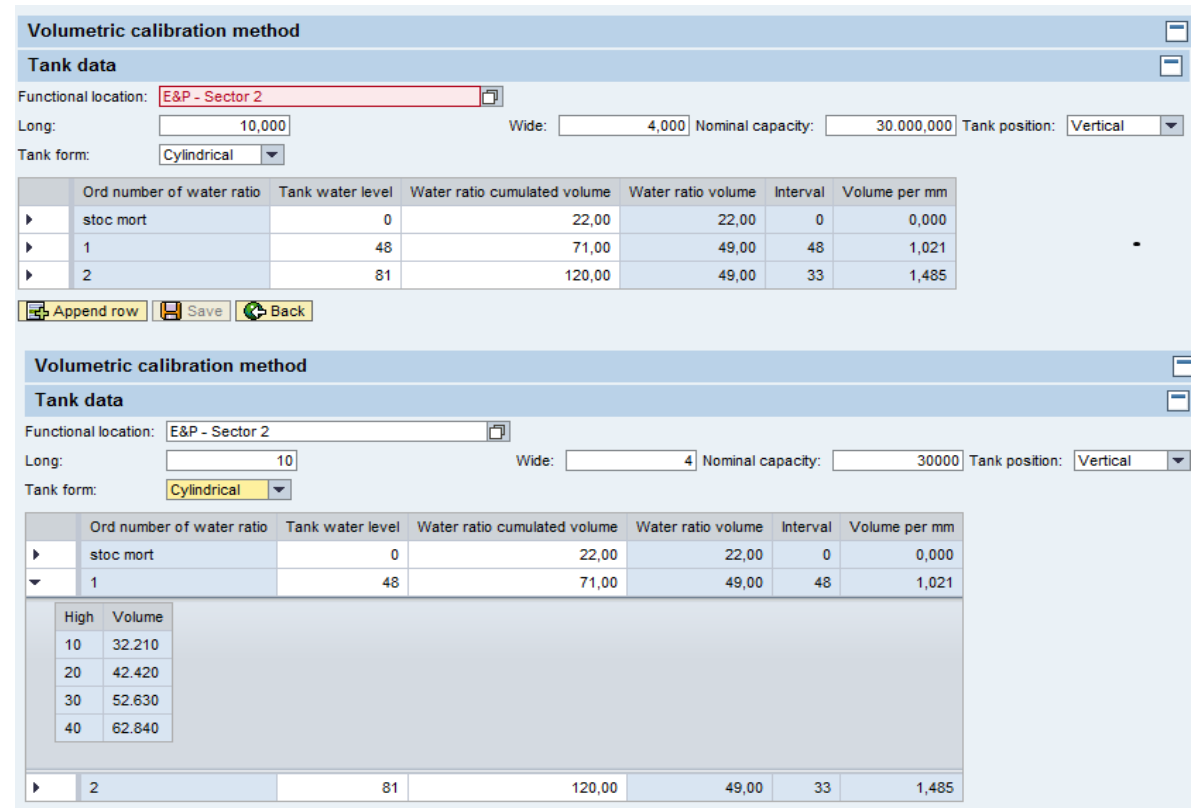

Figure 9. Metrology add new measurement

which is based on multiple manual measurements. The data previously mentioned, can be added automatically or manually. If the data is added manually, a calibration method will be established first, and only then the measurement can be started. The data is added in the system as described in Figure 9.

The

ZMET_TANK_METROLOGY transaction (in front of the ZMETTANKMETROLOGY program) is an example of "in house" z-application (all these SAP objects are included in one application package called ZOIL_TEST). This package contains all objects used in the SAP zapplication developed by the development team: Embedded Programs, Dictionary Objects, Class Library, Programs, Function groups, Includes, Transactions, SET / GET Parameters, Message Classes, Area Menus, Test Objects, Authorization Objects, Enhancements ([15]),
([16]). The Web Dynpro content (see Figure 10) for Metrology tool processing is a collection of screens, fields, menu bars, GUI status, GUI title, transactions, includes, flow logic - all used for metrology management processing inside the MET application. Two types of tables were used: first - the SAP standard tables and z-tables. All the tables are connected and are used for metrology management processing. All used metrology transactions refer to the WebDynpro technology / pool and to the initial screen. All programs are written using ABAP methodology and according with the company guideline and rules using Development Center tool [9], and, as a particular knowhow, the created code can be moved to other development systems, using Transport Organizer (se10 transaction), where we will create a big transport (transport of copies - because we have to add the

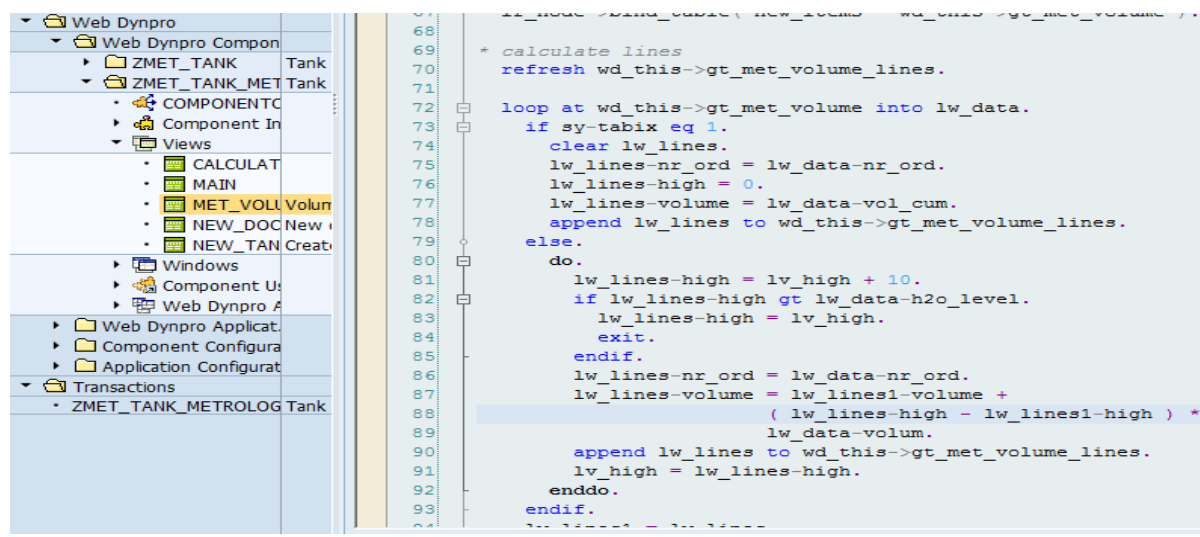

Figure 10. Metrology add new measurement 
corresponding target system) and we will include all created transports for dedicated development (report, form...etc.). The transport request will be added afterwards to the correspondent transport directory, in order to be included to the queue of target SAP system and imported in all systems in order to be visible for all SAP users.

\section{Conclusion}

The research performed in this paper, part of a $\mathrm{PhD}$ study, proved that a metrology system, fully and flexible auditable software tool, is a necessity for the evolution of ERP systems in an oil and gas company. The application presented in this paper is designed to solve problems (calibration reservoirs) in E\&P - in the area of metrology management. For our application, we composed three models: dispatcher model, body-leasing model, calibration given outside (fixed price). The authors developed and adapted a software system for storing, monitoring and reporting metrology data inside an existing SAP ERP integrated system. The application was developed and integrated in SAP (System and Application, Products) programming environment ABAP (Advanced Business Application Programming). An ABAP programming tool was used: WD WebDynpro (a web application framework - server-side runtime environment). The metrology software application is presently being used in a large oil and gas Company and handles the management of tank oil calibration. The paper started by presenting the steps used in tank oil calibration (metrology area) management and identified useful features in order to design successful software application in E\&P area.

\section{Acknowledgement}

The work has been funded by the Sectoral Operational Programme Human Resources Development 2007-2013 of the Ministry of European Funds through the Financial Agreement POSDRU/159/1.5/S/132397.

\section{REFERENCES}

1. KELLER, E. L., Lessons Learned, Manufacturing Systems, vol. 17(11), pp. 44-50.

2. CHEN, S. G. G., Y. K-K. LIN, Performance Analysis for Enterprise Resource Planning Systems, Industrial Engineering and Engineering Management, IEEM 2008, IEE International Conference, pp. 63-67.

3. LEU, J. D., L. T. HUANG, Logistics Planning of the IC Manufacturing Industry: A Method based on the SAPAPO , Computers \& Industrial Engineering, CIE 2009, pp. 760-766.

4. ZHOU, Y., SAP Business by Design, Data Engineering, ICDE 2009. IEEE 25th International Conference, p. 1760.

5. WEIDMANN, C., L. TEUBER, Conception and Installation of System Monitoring Using the SAP Solution Manager, 2009, Galileo Press.

6. PETER, M., T. POHL, Developing Enterprise Services for SAP, 2009, Galileo Press.

7. LIN, C. C., D. H. SHIH, Information System Reengineering for Enterprise Resource Planning as Businesses Adapting to the E-business Era, Software Engineering, WCSE 2009, WRI World Congress, vol. 3, pp. 222-226.

8. BANTA, V. C., D. COJOCARU, R. T. TANASIE, A Software Application for the Gas Transport and Distribution Management, Annals of the University of Craiova, Series: Automation, Computers, Electronics and Mechatronics, Vol. 10 (37), No. 2, 2012, ISSN 1841-0626, pages 1-6, Editura Universitaria, Craiova, 2013 (CNCSIS code 11 category $\mathrm{B}+$, internationally indexed, starting with 2010, BDI Copernicus, Inspec).

9. BANTA, V. C., D. COJOCARU, Development Center Tool a Software Application for Change Request Management, 17th International Conference on System Theory, Control and Computing Joint Conference SINTES 17, SACCS 13, SIMSIS 17, ISBN 978-1-47992228-4, ISBN 978-1-4799-2227-7, IEEE 
Catalog Number CFP1336P - CDR, Sinaia, Romania, 11-13 October 2013, pp. 42-47.

10. BANTA, V. C., D. COJOCARU, Calibration Oil Reservoirs - A Software Application for Metrology, International Conference on System Theory, Control and Computing ICSTCC 2014, SINTES 18, SACCS 14, SIMSIS 18, October 2014, Sinaia, Romania.

11. BANTA, V. C., D. COJOCARU, M. A. MOISESCU, I. S. SACALA, Release Management Tool - A Software Application for Release and Deployment Management, the 5th edition of the IACSIT / SCIEI / UASTRO International Conference on Optimization of the Smart systems and their Application in Aerospace, Robotics, Mechanical Engineering, Manufacturing Systems, Biomechanics, Neurorehabilitation and Human Motricities, ICMERA 201, Bucharest, Romania, October 2014.

12. COSTETCHI, N., A. M. STANESCU, M. A. MOISESCU, I. S. SACALA, V. C. BANTA, Focused - Liquid Enterprise System Architecture to Support e-Health Applications, 2014, Annals of the UPB, Series: Automation, Computers, Electronics and Mechatronics. HG No. 193/2002 and OG 20/1992

13. BRML, PIV 017-05-02 Metrological Procedure for Liquid Storage Tanks, Edition 1, Revision 0 / PV 017-05-01-07 Verification procedure for liquid storage tanks

14. SCHÄFER, M., M. MELICH, SAP Solution Manager, 2011, Galileo Press.

15. HELFEN, M., and TRAUTHWEIN, H.M., Testing SAP Solutions, 2010, Galileo Press. pp. 23-135.

16. KAPLAN, M., C. OEHLER, Implementing SAP Enhancement Packages, 2010, Galileo Press.
17. LEHNERT, V., K. BONITZ, L. JUSTICE, Authorizations in SAP Software: Design and Configuration, 2010, Galileo Press.

18. OROSZ, T., Analysis of SAP Development Tools and Methods, 2011, Intelligent Engineering Systems (INES), 15th IEEE International Conference, pp. 439-443.

19. JARDIM-GONCALVES, R., A. GRILO, C AGOSTINHO, F. LAMPATHAKI, Y. Charalabidis, Systematisation of Interoperability Body of Knowledge: The Foundation for Enterprise Interoperability as a Science, Enterprise Information Systems, vol. 6(3), 2012, pp. 1-26.

20. SACALA, I. S., M. A. MOISESCU, D. REPTA, Towards the Development of the Future Internet Based Enterprise in the Context of Cyber-Physical Systems, Control Systems and Computer Science (CSCS), 2013, pp. 405-412.

21. BANCIU, D., I. PETRE, D. M. SMADA, M. ANGHEL, Developing an Interactive System to Provide Management Support for Transportation Research Organizations, Studies in Informatics and Control, vol. 20(4), 2011, pp. 420-428.

22. MOISESCU M. A., I. S. SACALA, A. M. STANESCU, C. SERBANESCU, Towards Integration of Knowledge Extraction form Process Interoperability in Future Internet Enterprise Systems, Information Control Problems in Manufacturing, vol. 14(1), 2012 pp. 1458-1463.

23. BANCIU, D., R. M. BONCEA, C. I. ROTUNA, M. ANGHEL, Bringing EU Entrepreneurs together through Crossborder Services: SPOCS - a Case Study, Studies in Informatics and Control, vol. 21(3), 2012, pp. 303-314. 